\title{
Non-Dialysis Care: An Important Component of Care for Elderly Individuals with Advanced Stages of Chronic Kidney Disease
}

\author{
Sarbjit V. Jassal Elizabeth E. Kelman Diane Watson
}

University Health Network, Toronto, Ont., Canada

\section{Key Words}

Non-dialysis care $\cdot$ Conservative care $\cdot$ Maximal conservative management $\cdot$ Non-dialytic treatment

\begin{abstract}
Non-dialysis care (NDC) is the provision of all aspects of renal care except for the dialysis process. While the nomenclature may vary, with terms such as 'conservative care', 'maximal conservative management' or 'non-dialytic treatment' having been associated with NDC, the clinical principle is to provide comprehensive care to patients who opt to forgo dialysis despite increasing uraemic symptoms. NDC therapies focus on pain relief, the use of erythropoietin-stimulating agents, anti-pruritics and anti-nausea therapies, with lower emphasis on strategies used to modulate the rate of renal progression. Patient selection remains the most challenging aspect of developing an NDC program, with selection often being based on physician instinct, family principles and population-based prognostic risk measures. Outcomes are fair with a significant proportion of NDC patients experiencing lower hospitalization days and higher rates of death at home (or in a preferred environment) rather than in acute-care hospitals.

Copyright $\odot 2011$ S. Karger AG, Basel
\end{abstract}

\section{Introduction}

Much attention, in recent national and international conferences, has focused on the best way to provide optimal care to older individuals with chronic kidney disease (CKD) stages 4 and 5. One controversial, and often heated, discussion point is the suggestion that non-dialysis renal care (NDC) be promoted as an active treatment plan in vulnerable or older individuals. On the one hand, physicians and advocates in favour of non-dialysis care use data showing high mortality rates early after dialysis initiation, and the high morbidity burden experienced by those who survive, to argue a low benefit from dialysis in many cases. On the other hand, those who argue against NDC pathways, voice concerns about rationing, unfair ageism, and the creation of a system that limits free access to dialysis care. Those who oppose NDC cite data confirming that clinicians are often poorly able to identify patients who are unlikely to do well with dialysis. The purpose of this review is to focus on the role for NDC, distinguish between it and palliative care, and perhaps, offer practical suggestions that may be used by health care practitioners caring for older patients with CKD.

\section{KARGER}

Fax +4161306 1234 E-Mail karger@karger.ch www.karger.com
Dr. S.V. Jassal

University of Toronto and University Health Network

8NU-857, 200 Elizabeth St

Toronto, ON M5G 2C4 (Canada)

Tel. +1 416340 3196, E-Mail vanita.jassal@uhn.on.ca 


\section{Palliative Care Is Any Care That Puts Symptoms ahead of Disease Modification}

The literature often wrongly equates NDC with the term palliative care. While frequently complementary therapies, they are distinct philosophies. NDC refers only to the decision to forgo dialysis. Palliative care refers to the fact that the therapy is tailored to the management of symptoms and not designed to control the natural history of the disease. In his elegant review, Swidler [1] emphasizes two streams of palliative care - hospice and nonhospice care. He emphasizes that palliative care can be compatible with dialysis care under certain circumstances and describes the different components of care needed. This distinction is often overlooked despite its importance.

As mentioned in the previous paragraph, the term NDC is the provision of all aspects of renal care except for the dialysis process. The nomenclature is varied, with different programs using terms such as 'conservative care', 'maximal conservative management' or 'non-dialytic treatment' [2-8]. Regardless of terminology, each describes comprehensive care that is offered to patients who are becoming increasingly uraemic and opt to forgo dialysis. Although the treatments used to manage patients with CKD stages 3 and 4 are also NDC therapies, the focus changes from slowing of renal progression to limiting symptoms. Thus the focus is often more on the use of treatments such as erythropoietin-stimulating agents, anti-pruritics and anti-nausea therapies, and less so on angiotensin-converting enzyme inhibitors or dietary restrictions that effect change on the rate of renal progression. Unfortunately, the actual components of NDC have been left largely undefined in the literature, but generally, clinicians focus on three areas - managing the psychosocial burden of disease, managing both patient and family expectations of the process of dying and managing symptoms. (A discussion on some of the therapies that may be useful follows in a subsequent section.)

\section{Is There a Need for Palliative and Non-Dialysis Care?}

Recent studies demonstrate a modest survival of octogenarians starting dialysis in the US and in Canada [9, 10]. Dialysis care seems to be associated with a high burden of age-related problems such as frailty, falls and cognitive impairment [11]. While hard to attribute it to dialysis per se, patients seem to have an accelerated decline in function and/or cognition affecting the lives of both the patient and their caregivers $[12,13]$. Although it is distasteful to think of withholding dialysis purely on the basis of age, physicians must be responsible for offering care that promotes the best quality of life and not necessarily the longest duration of life [14]. Discussions by physicians about dialysis or transplantation often include information about the treatment itself but rarely consider how patients feel on dialysis, the differences between the dialysis treatments, or which of their usual activities they may be able to continue.

\section{Outcomes with NDC}

Although nephrologists in both Italy and France have published on the outcomes of patients who opt not to dialyze $[5,15]$, most publications advocating for NDC are from renal units within the UK $[2,3,16,17]$. Almost invariably, they suggest that NDC is an appropriate strategy for the most vulnerable or frail population. In a large comparative study, survival outcomes from 155 patients managed with NDC in a single centre (Lister Hospital, UK) were compared to those from 689 patients who were started onto dialysis therapy [4]. Although only a small percentage $(18 \%)$ of the total clinic population opted for NDC, $60 \%$ of those aged over 75 years chose not to dialyze. Modest differences in the median time to death were seen with dialysis care (prolongation of life by approximately $25 \%$ in both those with or without comorbidity). The survival curves for those treated with dialysis and those managed with NDC overlapped for patients known to have high levels of comorbidity, but the relatively small number of patients in this subgroup limited statistical power (power was estimated to be only $18 \%$ assuming 2 years of follow-up). In contrast, Carson et al. [3] found a significant difference in survival in their cohort of 204 patients (29 managed with NDC). Patients treated with dialysis had a median survival of 38 months compared to 14 months but also a higher rate of hospitalization (25 vs. 16 days per patient year). The authors argued that time spent admitted on an inpatient ward and travelling to and from dialysis as an outpatient was unusable from the patients' perspective. They therefore compared the number of days a patient spent alive, and free of hospital contact, with both NDC and dialysis care and found an almost equivalent number of hospital-free days in both groups with a considerably higher likelihood of dying at home in those with NDC. 


\section{Patient Selection}

The most challenging aspect of NDC is identifying patients who would be the most likely to have a difficult time on dialysis, and in whom NDC would be the most appropriate therapy. Centres most involved in NDC have shown that three components are needed: multidisciplinary team assessment, team-based recommendations and finally a series of detailed discussions with families and patients around dialysis and non-dialysis options [2]. Even if a strong recommendation is made for or against NDC, patients must be empowered to make an independent decision. Both the French and British experience suggests that around $12-18 \%$ of all CKD patients opt for NDC with a tendency for older patients to opt out of dialysis care more frequently $[3,4,15]$. In the Australian experience, the percentage is lower [18]. Almost $23 \%$ of patients in whom NDC was recommended chose to go ahead with dialysis [3]. These individuals would require ongoing support and encouragement to continue dialysis, as well as the option to withdraw at a later stage. Involvement of the patient, even if elderly or frail, is imperative, as often caregivers and health care workers underestimate the quality of a patient's life and overestimate their tolerance of their current health state $[19,20]$.

Clearly, defining the suitability of a patient for NDC poses a challenge. The thought of making the 'wrong decision' haunts every clinician and studies of physicians' attitudes show that individual physician comfort with recommending against dialysis varies both with age and experience [21]. Interestingly, a substantial number of physicians surveyed expressed regret over one or more previous decisions to offer or withhold dialysis. In general, clinicians tend to be more comfortable recommending NDC to older patients, particularly those who are socially isolated, dependent, or suffering from dementia or severe sequelae of stroke [2]. Burns et al. [2] recommend estimating survival benefits and including these in the discussion with the patient and family. Predictors of survival are, naturally, limited by the course of disease over time; however, two recent scores have relatively high validity $[22,23]$. In the first, a score system based on nine items (the presence or absence of diabetes mellitus, cardiac arrhythmias, active malignancy, low body mass index, grades 3 or 4 heart failure, severe peripheral vascular disease, dementia or behavioural disturbances, an unplanned start and total dependencies for transfer) predicted those with a $>70 \%$ chance of mortality at 6 months [22]. In the second model, the inclusion of the 'Surprise Question' increased the accuracy of the prediction $[23,24]$.
Conversations about NDC and dialysis withdrawal involve establishing a rapport whereby the patient can express their attitudes towards life and death, their fears and their desires. In fact, although most individuals accept death as an eventuality, most would wish for a comfortable and pain-free death, but are not able to visualize the continuum between survival and mortality.

Differences in acceptability of NDC across different racial, religious, cultural and educational strata need to be considered. In a small study from San Francisco, Kurella Tamura et al. [25] demonstrated that Blacks and those with lower education were less likely to engage in discussions on advanced care planning, or consider dialysis withdrawal after a catastrophic event. In contrast, the UK experience suggests little difference across cultural or social groups $[3,26]$.

Burns et al. [2] recommend four major themes around decision-making that are important for determining CKD treatment. These themes include confronting mortality, a patient's perception of lack of choice, the patient's need to gain knowledge (including that from peers), and the need to weigh alternatives. They report fewer than $1 \%$ of patients opting for their maximal conservative management programme change their mind when they start to become symptomatically uraemic [2].

Discussions around the options for dialysis and NDC need to occur over a period of time, ideally initiated as early as possible after diagnosis, with repeated meetings during which patients and families establish a trusting relationship with one or more health care professionals. Open, honest discussions should be held around issues such as symptoms and quality of life that a patient may expect; the frequency of interaction with the health care team, and the availability of support services over the duration of NDC. Patients should be given the opportunity and encouraged to ask 'How long will I live?', 'Where will I die?' and 'How will I die?'. Conversations about the experiences of others around the final days to weeks are important to both families who may experience guilt, doubt and anger even prior to their loved ones' death, and to patients who are often fearful of the coming days [2].

\section{Practical Issues for NDC}

Initially, much of NDC is similar to the care offered to the predialysis patient. Treatments include the use of erythropoietin-stimulating agents to maintain haemoglobin at current targets, dietary control of potassium and salt intake, and blood pressure control. Over time, 
however, the goals of care change and, towards the latter stages of management, there is little evidence to suggest dietary enforcement of phosphate or potassium restriction is beneficial. Blood pressure targets may also not be rigorously followed as patients are more prone to dizziness or falls and may actually find increased wellbeing with higher blood pressures and fewer medications. An ongoing objective assessment for postural symptoms is advised. One of the earliest consequences of the decision to opt for NDC is that patients do not need to be evaluated for, and undergo, vascular access creation in preparation for dialysis. While the 'timely' creation of a vascular access is an important quality indicator, there is increasing recognition that access placement may not always be appropriate for the frail older individual [27].

The most distressing symptoms commonly experienced by CKD patients in the month prior to death include a lack of energy (86\%), itch (84\%), drowsiness (82\%) and dyspnoea (80\%) [28]. Pain was present in $73 \%$ of patients followed, while gastro-intestinal symptoms, such as poor appetite, constipation and nausea, were common but described as being less severe ('little or somewhat disturbing'). Questionnaires such as the Memorial Symptom Assessment Scale-short form or the Edmonton symptom assessment system (ESAS) $[29,30]$ are useful tools to evaluate patients on an ongoing basis. Management of pain includes the use of simple analgesics, adjunct therapies and, in severe cases, opiates such as fentanyl, hydromorphone or methadone. Itch is difficult to control but may respond to emollients, capsaicin or topical preparations containing menthol and camphor in an emollient base. As renal failure progresses, it may be necessary to utilize additional medications such as scopol- amine to control secretions and nausea, or methotrimeprazine to help control clonus, which can be disturbing to both patient and family. Involvement of a palliative care team allows ongoing discussions around the patient and family expectations, and improves the recognition and treatment of symptoms such as loss of energy and constipation. It is important for the primary nephrologist to remain a part of the team, to provide support, and to advise the palliative care team regarding use of specific medications with renal failure. Some groups have developed 'emergency packages' which the patient is given to keep at home, containing medications such as intravenous or subcutaneous anti-emetics that may be administered by visiting nurses under the directive of the palliative-care physician.

Psychological support is a vital component of NDC, and requires empathetic listening skills, honesty, the gift of time, understanding of normal and pathological responses, and occasionally, referral to ancillary professionals. A team approach is recommended when embarking on the path of NDC, with those professionals best equipped to provide each domain of care. The decision to move toward NDC or palliative care may be fraught with many emotions, but if handled with knowledge, understanding and compassion, can be rewarding for the patient, their families, and for us as health care professionals.

\section{Disclosure Statement}

The authors have no conflicts of interest to declare.

\section{References}

1 Swidler M: Geriatric renal palliative care is coming of age. Int Urol Nephrol 2010;42: 851-855.

-2 Burns A, Davenport A: Maximum conservative management for patients with chronic kidney disease stage 5. Hemodial Int 2010; 14(suppl 1):S32-S37.

-3 Carson RC, Juszczak M, Davenport A, Burns A: Is maximum conservative management an equivalent treatment option to dialysis for elderly patients with significant comorbid disease? Clin J Am Soc Nephrol 2009;4:16111619.
4 Chandna SM, Silva-Gane M, Marshall C, Warwicker P, Greenwood RN, Farrington K: Survival of elderly patients with stage 5 CKD: comparison of conservative management and renal replacement therapy. Nephrol Dial Transplant 2010. Epub ahead of print.

- 5 De B, V, Tobaldini O, Boaretti C, Abaterusso C, Pertica N, Loschiavo C, Trabucco G, Lupo A, Gambaro G: Prolonged conservative treatment for frail elderly patients with endstage renal disease: the Verona experience. Nephrol Dial Transplant 2008;23:1313-1317.

-6 Ellam T, El Kossi M, Prasanth KC, El Nahas $\mathrm{M}$, Khwaja A: Conservatively managed patients with stage 5 chronic kidney disease outcomes from a single center experience. QJM 2009;102:547-554.
7 Smith C, Silva-Gane M, Chandna S, Warwicker P, Greenwood R, Farrington K: Choosing not to dialyse: evaluation of planned non-dialytic management in a cohort of patients with end-stage renal failure. Nephron Clin Pract 2003;95:c40-c46.

-8 Wong CF, McCarthy M, Howse ML, Williams PS: Factors affecting survival in advanced chronic kidney disease patients who choose not to receive dialysis. Ren Fail 2007; 29:653-659.

-9 Jassal SV, Trpeski L, Zhu N, Fenton SSA, Hemmelgarn BR: Changes in survival over the years 1990-1999 for elderly patients initiating dialysis. Can Med Assoc J 2007;177: 1033-1038. 
10 Kurella M, Covinsky KE, Collins AJ, Chertow GM: Octogenarians and nonagenarians starting dialysis in the United States. Ann Intern Med 2007;146:177-183.

11 Jassal SV, Watson D: Dialysis in late life: benefit or burden. Clin J Am Soci Nephrol 2009; 4:2008-2012.

-12 Jassal SV, Chiu E, Hladunewich MA: Loss of independence in patients starting dialysis at 80 years of age or older. N Engl J Med 2009; 361:1612-1613.

-13 Kurella Tamura M, Covinsky KE, Chertow GM, Yaffe K, Landefeld CS, McCulloch CE: Functional Status of Elderly Adults before and after Initiation of Dialysis. N Engl J Med 2009;361:1539-1547.

14 Jassal SV, Watson D: Doc, don't procrastinate... Rehabilitate, palliate, and advocate. Am J Kidney Dis 2010;55:209-212.

- 15 Joly D, Anglicheau D, Alberti C, Nguyen AT, Touam M, Grunfeld JP, Jungers P: Octogenarians reaching end-stage renal disease: $\mathrm{co}^{-}$ hort study of decision-making and clinical outcomes. J Am Soc Nephrol 2003;14:10121021.

-16 Smith C, Silva-Gane M, Chandna S, Warwicker P, Greenwood R, Farrington K: Choosing not to dialyse: evaluation of planned non-dialytic management in a cohort of patients with end-stage renal failure. Nephron Clin Pract 2003;95:c40-c46.

-17 Murtagh FE, Marsh JE, Donohoe P, Ekbal NJ, Sheerin NS, Harris FE: Dialysis or not? A comparative survival study of patients over 75 years with chronic kidney disease stage 5 . Nephrol Dial Transplant 2007;22:19551962.
18 Morton RL, Howard K, Webster AC, Snelling P: Patient INformation about Options for Treatment (PINOT): a prospective national study of information given to incident CKD stage 5 patients. Nephrol Dial Transplant 2011;26:1266-1274.

19 Tsevat J, Dawson NV, Wu AW, Lynn J, Soukup JR, Cook EF, Vidaillet H, Phillips RS: Health values of hospitalized patients 80 years or older. HELP Investigators. Hospitalized Elderly Longitudinal Project. JAMA 1998;279:371-375

20 Tsevat J, Cook EF, Green ML, Matchar DB, Dawson NV, Broste SK, Wu AW, Phillips RS, Oye RK, Goldman L: Health values of the seriously ill. SUPPORT investigators. Ann Intern Med 1995;122:514-520.

21 Clement R, Chevalet P, Rodat O, OuldAoudia V, Berger M: Withholding or withdrawing dialysis in the elderly: the perspective of a western region of France. Nephrol Dial Transplant 2005;20:2446-2452.

22 Couchoud C, Labeeuw M, Moranne O, Allot V, Esnault V, Frimat L, Stengel B: A clinical score to predict 6-month prognosis in elderly patients starting dialysis for end-stage renal disease. Nephrol Dial Transplant 2009; 24:1553-1561.

23 Cohen LM, Ruthazer R, Moss AH, Germain MJ: Predicting six-month mortality for patients who are on maintenance hemodialysis. Clin J Am Soc Nephrol 2010;5:72-79.
24 Moss AH, Ganjoo J, Sharma S, Gansor J, Senft S, Weaner B, Dalton C, MacKay K, Pellegrino B, Anantharaman P, Schmidt R: Utility of the 'surprise' question to identify dialysis patients with high mortality. Clin J Am Soc Nephrol 2008;3:1379-1384.

25 Kurella Tamura M, Goldstein MK, PerezStable EJ: Preferences for dialysis withdrawal and engagement in advance care planning within a diverse sample of dialysis patients. Nephrol Dial Transplant 2010;25:237-242.

-26 Chandna SM, Schulz J, Lawrence C, Greenwood RN, Farrington K: Is there a rationale for rationing chronic dialysis? A hospital based cohort study of factors affecting survival and morbidity. BMJ 1999;318:217-223.

-27 O'Hare AM, Bertenthal D, Walter LC, Garg AX, Covinsky K, Kaufman JS, Rodriguez RA, Allon M: When to refer patients with chronic kidney disease for vascular access surgery: should age be a consideration? Kidney Int 2007;71:555-561.

28 Murtagh FE, Addington-Hall J, Edmonds P, Donohoe P, Carey I, Jenkins K, Higginson IJ: Symptoms in the month before death for stage 5 chronic kidney disease patients managed without dialysis. J Pain Symptom Manage 2010;40:342-352.

29 Davison SN, Jhangri GS, Johnson JA: Longitudinal validation of a modified Edmonton symptom assessment system (ESAS) in haemodialysis patients. Nephrol Dial Transplant 2006;21:3189-3195.

>30 Davison SN, Jhangri GS, Johnson JA: Crosssectional validity of a modified Edmonton symptom assessment system in dialysis patients: a simple assessment of symptom burden. Kidney Int 2006;69:1621-1625. 